\title{
The CU mobile Solar Occultation Flux instrument: structure functions and emission rates of $\mathrm{NH}_{3}, \mathrm{NO}_{2}$ and $\mathrm{C}_{2} \mathrm{H}_{6}$
}

Natalie Kille et al.

Correspondence to: R. Volkamer (rainer.volkamer@colorado.edu)

The copyright of individual parts of the supplement might differ from the CC-BY 3.0 licence. 

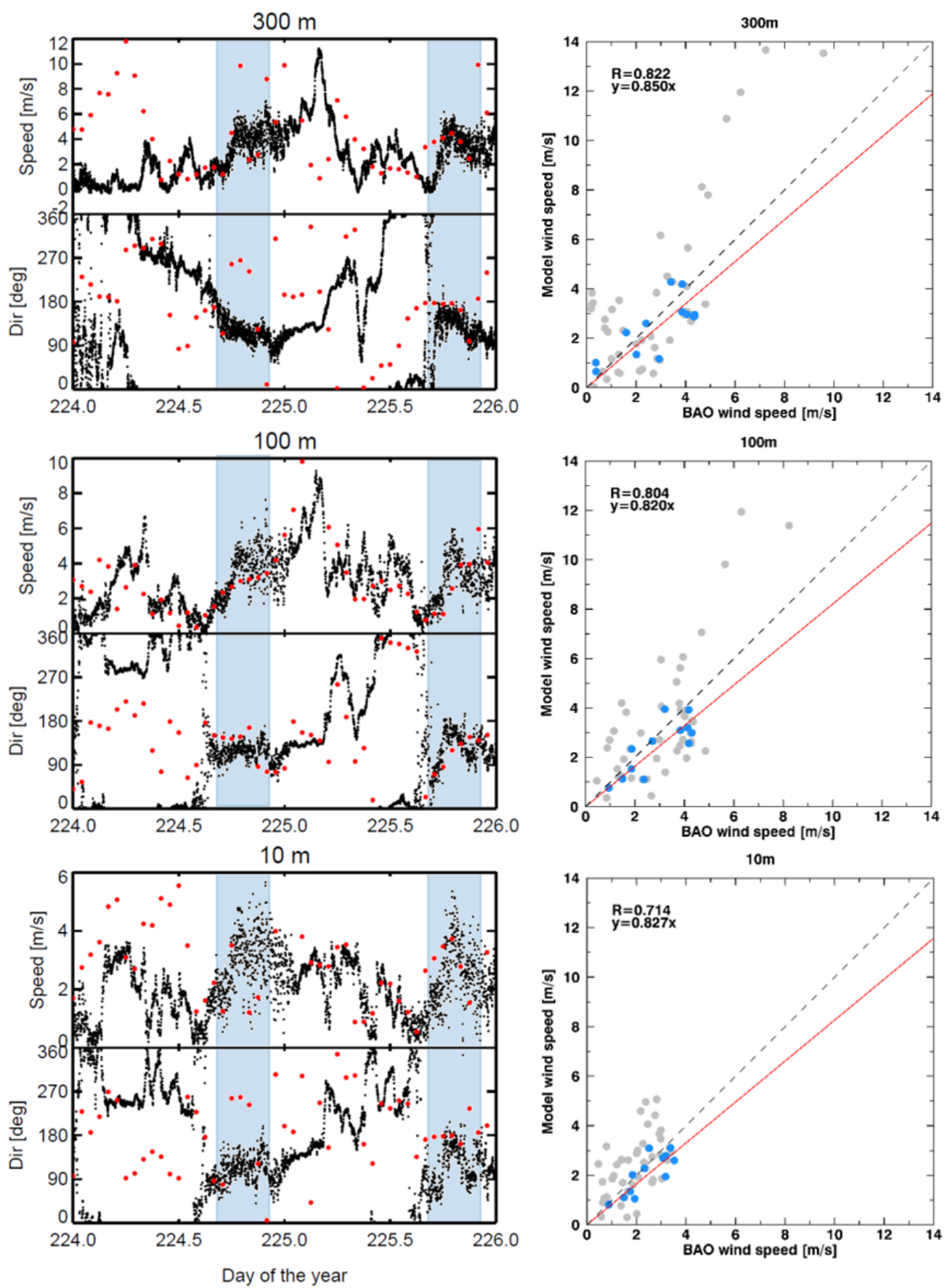

25 Figure S1: Comparison of wind speed and wind direction at 300 (top), 100 (middle), and $10 \mathrm{~m}$

26 (bottom). Left column: Black is BAO observed wind, red is modeled wind for 12 and 13 August

27 2014. The colored shading indicates the times of the RDs on both days (16-22 UTC). Right 28 column: Blue indicates data from 16-22 UTC, gray is all data. The red line indicates the fit to 29 blue data, the dashed line is the 1:1 line. 


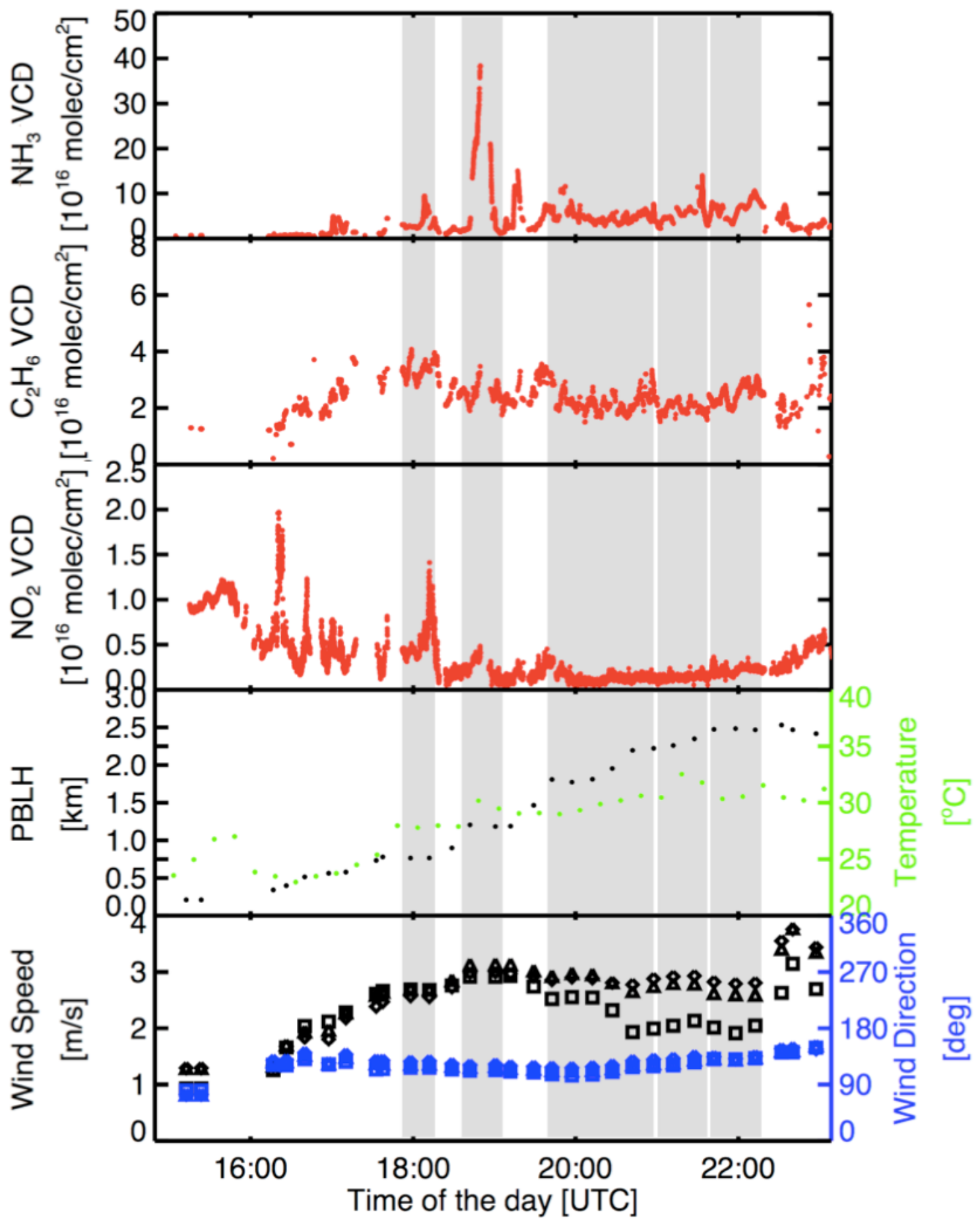

31 Figure S2: Timeseries of the VCDs measured for A) $\left.\mathrm{NH}_{3}, \mathrm{~B}\right) \mathrm{C}_{2} \mathrm{H}_{6}$, C) $\mathrm{NO}_{2}$, during RD10. D)

32 PBLH and temperature, E) model wind; (diamonds) model wind averaged over approximately 10

$33-50 \mathrm{~m}$ above ground level, (triangles) over half PBLH, (squares) over the full PBLH. Shaded 34 areas indicate times at each site. 

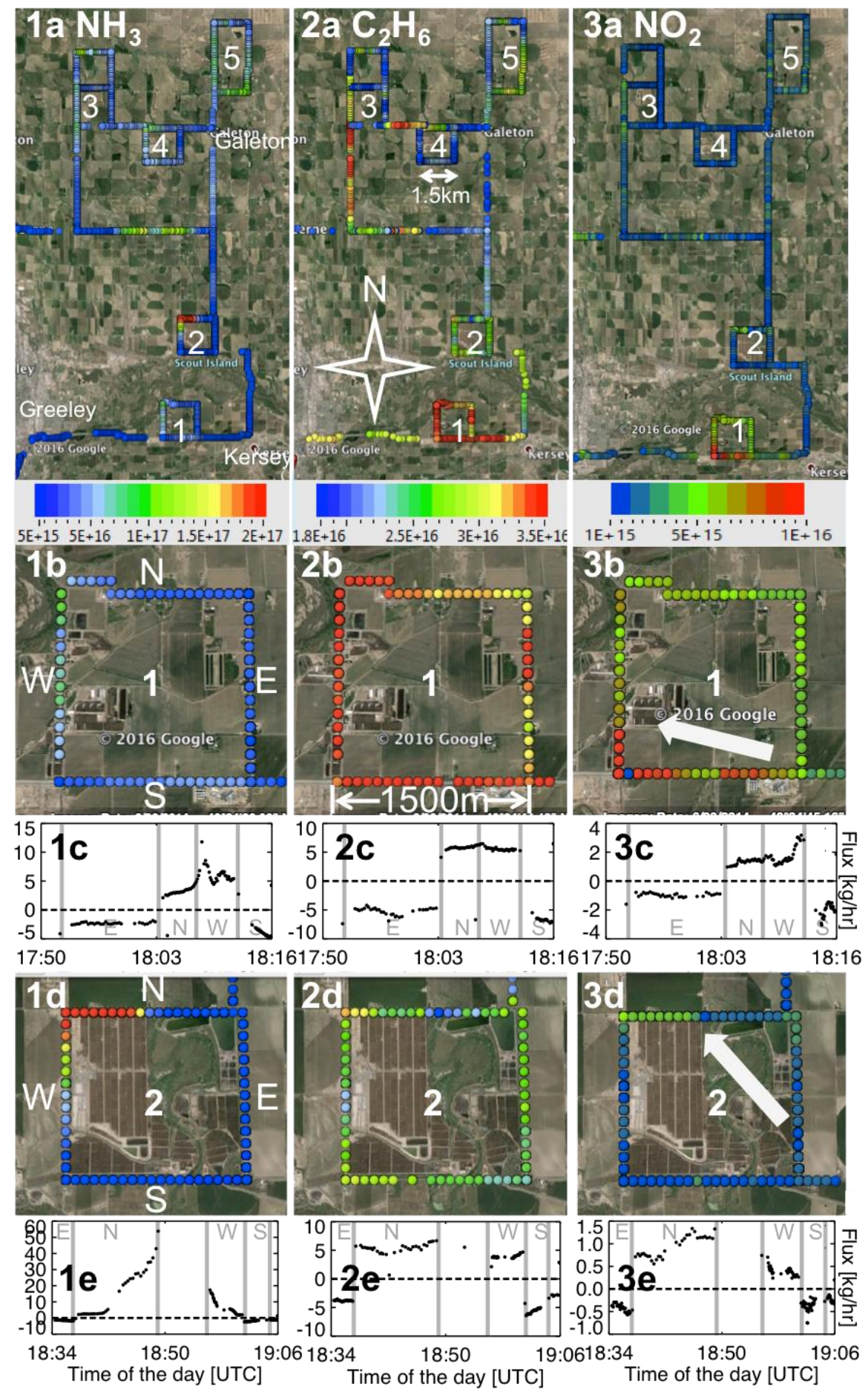

36 Figure S3: Zoom of the area east of Greeley, CO with the RD10 drive track color coded by the

37 VCD of (left column, 1) $\mathrm{NH}_{3}$, (middle, 2) $\mathrm{C}_{2} \mathrm{H}_{6}$, and (right, 3) $\mathrm{NO}_{2}$. Row (a) shows the 5 sites of

38 interest, (b) site 1, (d) site 2 from Fig. 6. Rows (c) and (e) show a timeseries of the flux,

39 calculated using equation (1); the arrows in $3 \mathrm{~b}$ and $3 \mathrm{~d}$ indicate the mean wind direction at each

40 site. (Background image from Google Earth 2016) 

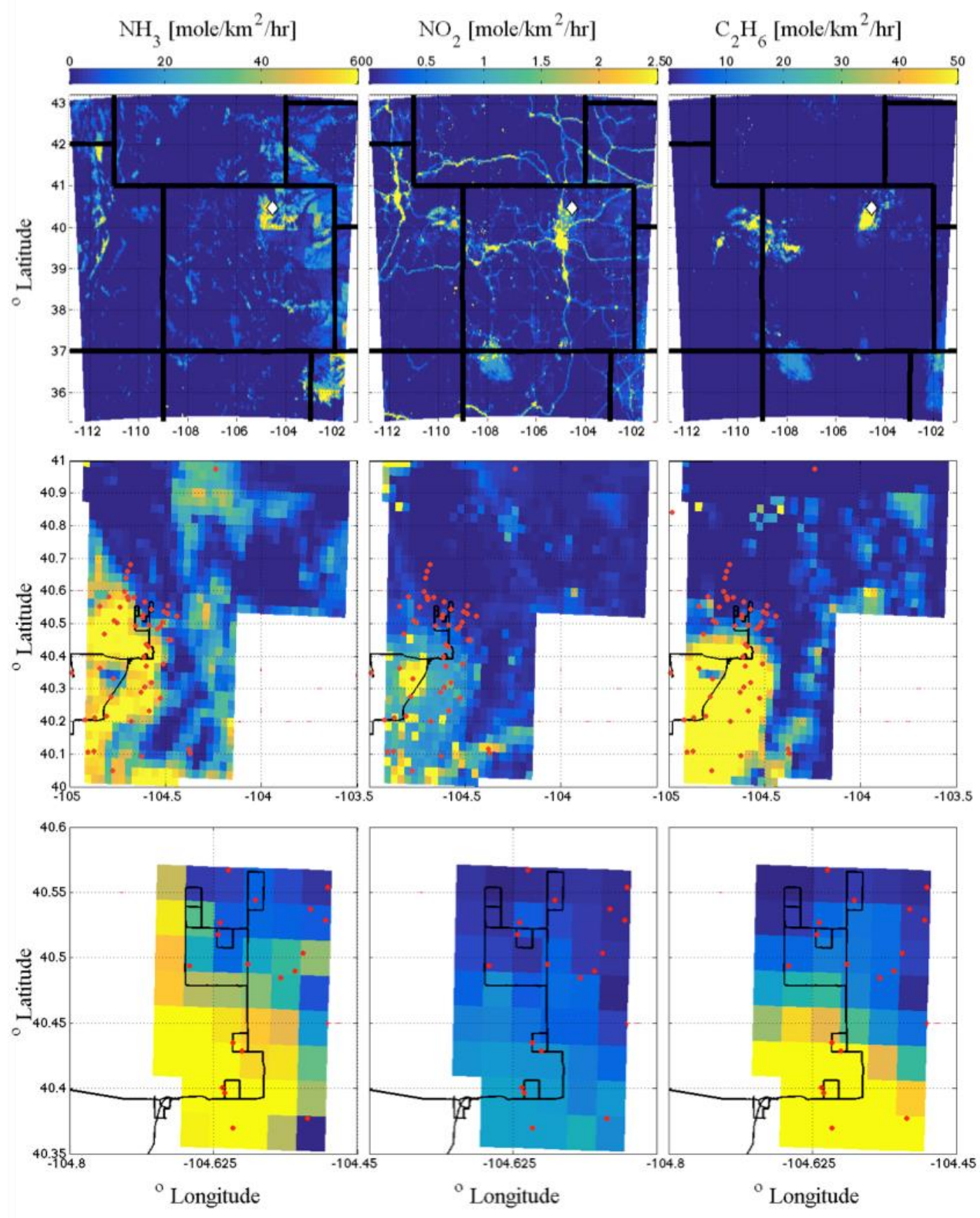

42 Figure S4: Emission Inventory (EPA, 2015) based on the July midday hourly emission rate

43 during which $\mathrm{NH}_{3}$ emission is larger than during other hours. $\mathrm{NH}_{3}$ (left), $\mathrm{NO}_{2}$ (center), and $\mathrm{C}_{2} \mathrm{H}_{6}$ 44 (right); the bold black lines in the top panel indicate the state borders with Colorado in the center; 45 the red dots in the middle and bottom panels indicate cattle and dairy farm locations, and the 46 black line the research drive track. 